\title{
Ethanol Production from Glycerol using Pachysolen tannophilus in a Surface-aerated Fermentor
}

\author{
Yi-Ok Kim', Woon-Yong Choi ${ }^{2}$, Do-Hyung Kang ${ }^{3}$, Hyeon-Yong Lee ${ }^{4}$, and Kyung-Hwan Jung ${ }^{1}$ * \\ ${ }^{1}$ Department of Biotechnology, ${ }^{+}$Korea National University of Transportation, Jeungpyung, Chungbuk 368-701, Korea \\ ${ }^{2}$ Department of Medical Biomaterials Engineering Kangwon National University, Chunchean 200-701, Korea \\ ${ }^{3}$ Korea Institute of Ocean Science and Technology, Ansan, Gyeonggi-do 426-744, Korea \\ ${ }^{4}$ Department of Food Science and Engineering, Seowon University, Cheongiu, Chungbuk 361-742, Korea
}

Received May 3, 2013 /Revised June 27, 2013 /Accepted July 8, 2013

\begin{abstract}
We investigated ethanol production from glycerol after screening of the yeast Pachysolen tannophilus ATCC 32691. For yeast to produce ethanol form glycerol, it is important that aeration is finely controlled. Therefore, we attempted to produce ethanol using a surface-aerated fermentor. When 880 $\mathrm{ml}$ of YPG medium (1\% yeast extract, $2 \%$ peptone, $2 \%$ glycerol) was used to produce ethanol, the optimal aeration conditions for ethanol production were a surface aeration rate and agitation speed of $500 \mathrm{ml} / \mathrm{min}$ and $300 \mathrm{rpm}$, respectively. In a fed-batch culture, the maximum ethanol production and the maximum ethanol yield from glycerol (Ye/g) was $5.74 \mathrm{~g} / 1$ and 0.166 , respectively, after 90 hr using the surface-aerated fermentor.
\end{abstract}

Key words : Ethanol, fed-batch culture, glycerol, Pachysolen tannophilus, surface aeration

\section{서 론}

Biodiesel은 다양한 지방 자원(oil feedstock)으로 부터 transesterification 반응에 의하여 생산되어 바이오연료로 사용되어 지고 있다 $[1,7,16]$. 이때 부산물로서 glycerol이 생성 되는데, 이를 탄소원으로 이용하여 보다 유용한 산물을 만들기 위한 연구가 활발히 이루어지고 있다[2, 8, 15]. 그 중에서도 glycerol 을 이용하여 ethanol을 생산하려는 전략은 지방 자원을 biodiesel과 ethanol 같은 바이오 연료로 완전히 전환한다는 의미 에서 큰 관심의 대상이 되고 있다 $[6,12,13]$. 또한 glycerol을 이용한 ethanol 생산과 옥수수 유래 전분을 이용한 ethanol 생 산의 경제성을 분석하여 보았을 때, 전체 비용에서 glycerol을 이용한 ethanol 생산 비용이 전분을 이용한 것에 비하여, 약 $62 \%$ 정도에 불과하다는 분석 보고가 있어서[18], glycerol에서 ethanol로의 전환에 더 더욱 많은 관심이 모아지고 있다.

Glycerol로 부터 ethanol 생산은 세균 $[5,6,14]$ 과 효모[12, 13]를 이용하는 방법이 보고되고 있는데, 세균을 이용하는 방 법은 공기가 없는 조건에서 anaerobic fermentation으로 이루

\footnotetext{
${ }^{\dagger}$ Korea National University of Transportation is formerly Chungju National University

*Corresponding author

Tel : +82-43-820-5246, Fax : +82-43-820-5272

E-mail : khjung@cjnu.ac.kr

This is an Open-Access article distributed under the terms of the Creative Commons Attribution Non-Commercial License (http://creativecommons.org/licenses/by-nc/3.0) which permits unrestricted non-commercial use, distribution, and reproduction in any medium, provided the original work is properly cited.
}

어지며, 대사경로와 redox balance 등이 어느 정도 잘 이해되 어지고 있다[18]. 반면에, 효모의 경우에는 일반적으로 glyceol 이 fermentable 탄소원으로 사용되어지지 않는 것으로 알려져 왔음에도 불구하고, 효모 Pachysolen tannophilus (P. tannophilus)가 glycerol을 이용하여 ethanol을 생성한다는 보고가 발표 되었다[12, 13].

효모가 glycerol을 이용할 때, 첫 번째 효소인 glycerol kinase에 의하여 glycerol을 glycerol-3-phosphate (G3P)로 전환 시키고, 이 G3P가 미토콘드리아에 있는 FAD-dependent glycerol-3-phosphate dehydrogenase에 의해서 dihydroxyacetone phosphate로 산화되는 것으로 알려져 있다 $[9,10]$. 그런데, 이 때 산소가 어느 정도 공급되어야 이 산화반응이 진행되는 것 으로 알려져 있는데, 그 이유는 FAD-dependent glycerol-3-phosphate dehydrogenase가 미토콘드리아의 전달전달 계로 전자를 전달하는 역할을 하고 있기 때문인 것으로 알려 져 있다. 이러한 이유 때문에 세균과는 다르게 Pachysolen tannophilus는 공기가 없는 조건에서는 glycerol로 부터 ethanol을 생성하지 못하고, 공기가 있는 조건에서만 ethanol을 생성한 다는 연구 결과가 나왔으며[13], 또한 Liu 등[12]의 연구 결과 에서도 같은 이유로 $0.083 \mathrm{vvm}$ 정도의 적은 양의 공기를 주입 하였을 때, 가장 많은 ethanol을 생성하는 결과를 얻게 된 것으 로 생각되어진다.

한편, 본 연구에 사용할 glycerol로 부터 ethanol을 생성하 는 효모를 선별하기 위하여, 몇 가지 효모를 수집하였다. 먼저 Maleszka 등[13]의 보고에 효모 Candida가 배양 중에 일시적 으로 ethanol을 생산 한다는 연구 결과를 소개하였기에, 이를 바탕으로 Candida와 유사한 생리적 특성을 지니고 있고, xy- 
lose와 같은 5 탄당을 이용 할 수 있는 효모를 국내기탁기관에 서 수집하였고(Table1), 본 연구팀의 선행연구에 사용하였던 xylose 이용 효모도 포함시켰다[11, 19, 20]. Table 1과 같은 6가지 효모 중에서 glycerol로 부터 ethanol을 생산할 수 있는 효모를 선별하고, 이를 이용하여 glycerol로 부터 ethanol을 발효조에서 생산하는 방법을 조사하였다. 이때, 적은양의 공 기를 공급하기 위하여 surface aeration 방법을 사용하였고, surface aeration 방법은 xylose와 같은 5탄당 탄소원을 효모가 이용할 때, 본 연구팀에서 사용한 미량 공기 공급방법으로 사 용한 방법이다[11, 19, 20]. 최종적으로 glycerol이 포함된 배지 를 이용하여 fed-batch 배양을 실시하여, surface aeration 방법 을 통한 공기 공급으로 ethanol 생산이 가능한지를 확인하였다.

\section{재료 및 방법}

Yeast strains와 chemicals

Table 1과 같이 국내 기탁기관(한국생명공학연구원 미생물 자원센터, 한국미생물보존센터)에서 구할 수 있는 효모를 본 실험에 사용하였다. Glycerol은 Bio Basic Canada Inc. (Markham, ON, Canada)에서 yeast extract와 peptone은 Becton Dickinson (Sparks, MD, USA)에서 구입하였으며, glycerol 분석용 시약인 sodium periodate, ammonium acetate는 Junsei Chemical Co. (Tokyo, Japan)와 Samchun Chemical Co. (Seoul, Republic of Korea)에서, acetic acid와 acetyl acetone은 Daejung Chemical Co. (Gyeonggi-Do, Republic of Korea)에서 구입하여 사용하였다.

\section{Flask culture}

Seed culture는 $300 \mathrm{ml}$ 삼각 flask에 $50 \mathrm{ml}$ 의 YPD (1\% yeast extract, $2 \%$ peptone, $2 \%$ dextrose) 배지를 준비한 후, shaking incubator에서 실시하였다. Glycerol이 들어간 배지를 사용하 는 본 배양은 $300 \mathrm{ml}$ 삼각 flask에 $20 \mathrm{ml}$ 의 YPG (1\% yeast extract, $2 \%$ peptone, $2 \%$ glycerol) 배지에 실시하였는데, $10 \%$ 의 seed culture를 접종하여 shaking incubator에서 배양을 시 작하였다. 배양할 때, 온도는 $30^{\circ} \mathrm{C}$ 로 조절하였다.

Surface-aerated fermentor culture

P. tannophilus ATCC 32691의 seed culture를 $300 \mathrm{ml}$ 삼각 flask에 $80 \mathrm{ml}$ 의 YPD 배지를 사용하여 shaking incubator에서 기른 후 $\left(30^{\circ} \mathrm{C}, 150 \mathrm{rpm}\right), 800 \mathrm{ml} \mathrm{YPG}$ 배지가 들어있는 2.5 l-jar fermentor (Korea Fermentor)에 접종하였다. 이때, 공기는 Fig. 1과 같은 surface aeration 방법을 이용하여 공급하였고, 배양온도는 $30^{\circ} \mathrm{C}, \mathrm{pH}$ 는 $20 \%$ 인산과 암모니아수를 이용하여 5.0 으로 조절하였다. 기본적으로 $500 \mathrm{ml} / \mathrm{min}$ 의 공기를 surface aeration 방법으로 공급하였고, agitation speed는 200-400 $\mathrm{rpm}$ 범위에서 변화를 주었다. Fed-batch culture를 실시할 때 에는 $1 \%$ yeast extract와 $2 \%$ peptone을 포함하는 용액 100 $\mathrm{ml}$ 에 $100 \mathrm{~g}$ 의 glycerol을 섞어 혼합한 배지를 첨가하였다.

\section{분석방법}

효모의 성장은 spectrophotometer를 이용하여 optical density를 $600 \mathrm{~nm}\left(\mathrm{OD}_{600}\right)$ 에서 측정하여 모니터링 하였고, glycerol은 chemical assay 방법을 이용하여 정량하였다[4]. 그리고 ethanol은 gas chromatography를 이용하여 정량분석 하였고, 자세한 조건은 선행연구에 설명하였다[20]. 산소전달계수 (oxygen transfer coefficient, $\mathrm{k}_{\mathrm{L}}$ ) 는 unsteady-state method를 이용하여 측정하였다[17].

\section{수율 계산}

수율 $\mathrm{Ye} / \mathrm{g}, \mathrm{Ye} / \mathrm{x}, \mathrm{Yx} / \mathrm{g}$ 는 아래의 식에 의해서 계산되었다. 이때 $\Delta \mathrm{E}, \Delta \mathrm{G}, \Delta \mathrm{X}$ 는 배양 중의 ethanol, glycerol, 세포농도의 최고값과 최저값의 변화량이며, 세포농도는 $\mathrm{OD}_{600}$ 값을 건조

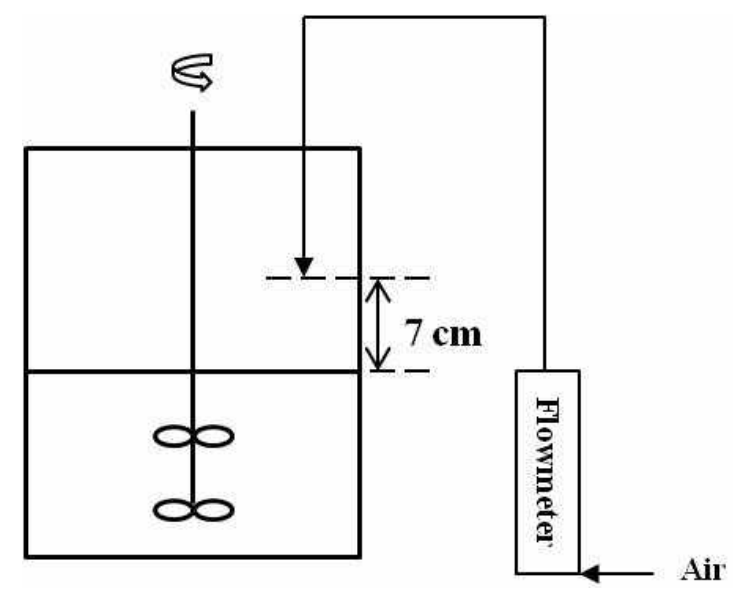

Fig. 1. Surface-aerated fermentor.

Table 1. Yeast strains used in this study

\begin{tabular}{lll}
\hline Yeasts & KCTC No. & ATCC/CBS No. \\
\hline Pachysolen tannophilus & KCTC 7229 & ATCC 32691 \\
Candida tropicalis & KCCM 50553 & ATCC 20326 \\
Candida shehatae & KCCM 12012 & ATCC 58779 \\
Pichias tipitis & KCTC 7222 & ATCC 58376 \\
Pichias tipitis & KCTC 7228 & ATCC 58784 \\
Pichias tipitis & & CBS 7126 \\
\hline
\end{tabular}


균체량으로 환산하여 사용하였다.

$$
\begin{aligned}
& Y_{e / g}=\frac{\Delta E}{\Delta G} \\
& Y_{e / x}=\frac{\Delta E}{\Delta X} \\
& Y_{x / g}=\frac{\Delta X}{\Delta G}
\end{aligned}
$$

\section{결과 및 고찰}

Glycerol로 부터 ethanol을 생산하는 효모 선별

6가지의 효모를 사용하여 glycerol로부터 ethanol을 생산 할 수 있는 효모를 선별하였다. Fig. 2와 같이 6가지 효모에 대하여 glycerol이 약 $20 \mathrm{~g} / 1$ 포함된 배지에서 ethanol 생산을 확인한 결과 P. tannophilus ATCC 32691에서 glycerol을 소비 하면서 가장 많은 양의 ethanol인 약 $3.5 \mathrm{~g} / 1$ 를 생산 할 수 있다는 것을 확인할 수 있었다. 반면에 다른 효모에서는 Maleszka 등[13]의 보고와 같이 아주 적은 양의 ethanol이 일 시적으로 생산되는 것을 볼 수 있었다. 이미 Maleszka 등[13] 의 연구결과에서 P. tannophilus NRRL Y-2640의 glycerol로 부터 ethanol 생산이 보고되었고, 또한 Liu 등[12]도 $P$. tannophilus CBS 4044의 glycerol로 부터 ethanol 생산을 보고하였 다. 그런데, 국내기탁기관의 자료로부터 P. tannophilus NRRL Y-2640과 P. tannophilus CBS 4044를 확인하여 본 결과 이 두 효모는 Fig. 2에서 가장 ethanol을 많이 생산하는 효모인 $P$. tannophilus ATCC 32691와 동일한 효모임을 확인할 수 있었 다. 그래서, 본 연구에서는 이 효모를 이용하여 glycerol로 부 터 ethanol을 생산하는 연구를 수행하였다.

이미 언급하였듯이 효모 P. tannophilus를 이용하여 ethanol 을 생산 할 경우에 공기의 공급이 매우 중요하기 때문에, 먼저 공기의 공급이 ethanol 생산에 어떠한 영향을 미치는지에 대 하여 확인하기 위하여, shaking incubator에서 glycerol이 약 $20 \mathrm{~g} / 1$ 포함된 배지를 사용하여 ethanol 생산 실험을 실시하였 다(Table 2). 이때 효모 P. tannophilus ATCC 32691를 사용하였 으며, 4 개 flask culture의 shaking speed를 50, 100, 150, 200
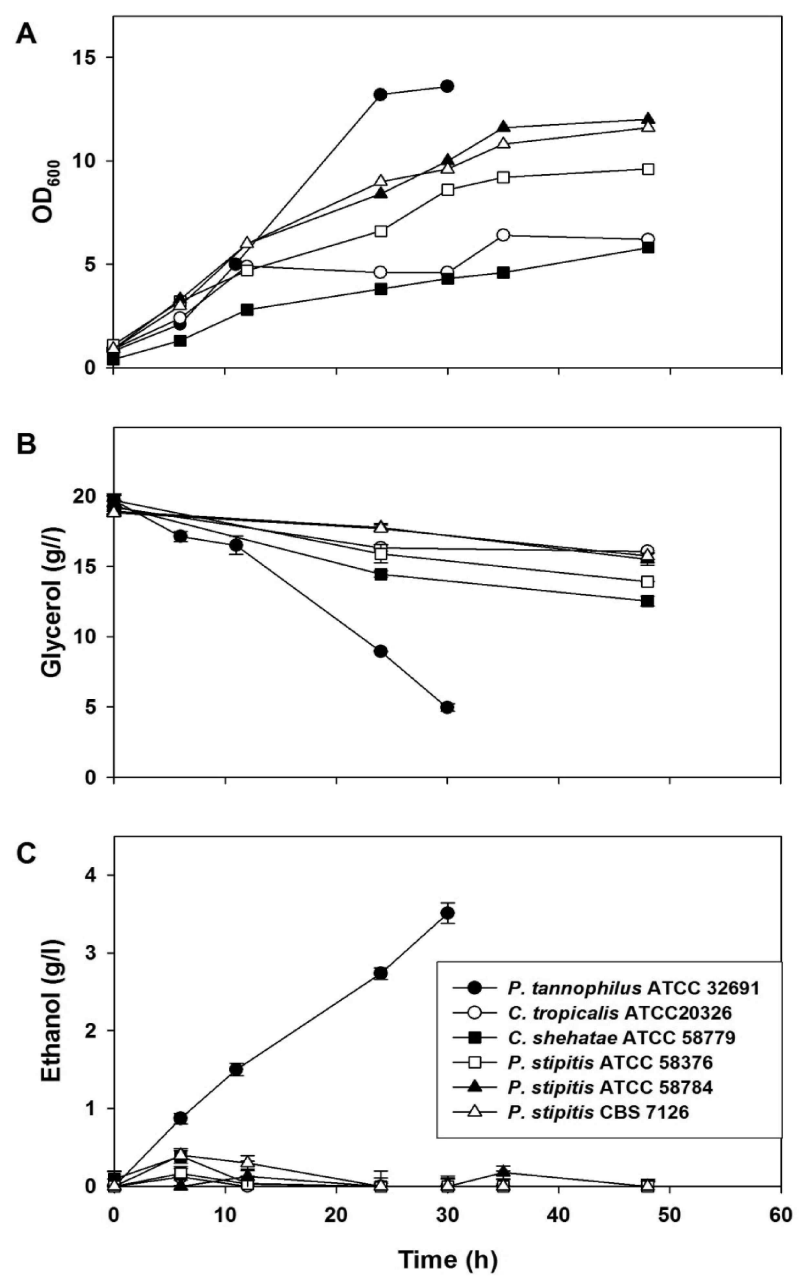

Fig. 2. Shaking flask cultures for selecting a yeast capable of ethanol production from glycerol. Measurements of glycerol and ethanol were performed three times using the same sample, and the average and standard deviation were calculated.

$\mathrm{rpm}$ 까지 변화시키면서 세포성장, glycerol 소비, ethanol 생산 을 관찰하였다. Shaking speed를 50, 100, $150 \mathrm{rpm}$ 까지 증가시 켰을 때, 세포성장은 shaking speed 증가에 따라서 더 증가하 였고, glycerol의 소비도 더 잘 일어났으며, 48 시간 지난 후의 최종 ethanol의 생산도 shaking speed 증가에 따라서 1.16,

\begin{tabular}{|c|c|c|c|c|c|c|c|c|c|c|c|c|}
\hline \multirow{3}{*}{$\begin{array}{l}\text { Time } \\
(\mathrm{hr})\end{array}$} & \multicolumn{12}{|c|}{ Shaking speed (rpm) } \\
\hline & \multicolumn{3}{|c|}{50} & \multicolumn{3}{|c|}{100} & \multicolumn{3}{|c|}{150} & \multicolumn{3}{|c|}{200} \\
\hline & $\mathrm{OD}_{600}$ & $\begin{array}{c}\text { Glycerol } \\
(\mathrm{g} / \mathrm{l})\end{array}$ & $\begin{array}{c}\text { Ethanol } \\
(\mathrm{g} / \mathrm{l})\end{array}$ & $\mathrm{OD}_{600}$ & $\begin{array}{c}\text { Glycerol } \\
(\mathrm{g} / \mathrm{l})\end{array}$ & $\begin{array}{c}\text { Ethanol } \\
(\mathrm{g} / \mathrm{l})\end{array}$ & $\mathrm{OD}_{600}$ & $\begin{array}{c}\text { Glycerol } \\
(\mathrm{g} / \mathrm{l})\end{array}$ & $\begin{array}{c}\text { Ethanol } \\
(\mathrm{g} / \mathrm{l})\end{array}$ & $\mathrm{OD}_{600}$ & $\begin{array}{c}\text { Glycerol } \\
(\mathrm{g} / \mathrm{l})\end{array}$ & $\begin{array}{c}\text { Ethanol } \\
(\mathrm{g} / \mathrm{l})\end{array}$ \\
\hline 14 & 1.4 & 17.4 & 0.70 & 4.9 & 16.4 & 0.90 & 5.5 & 14.5 & 0.75 & 6.3 & 15.1 & 0.75 \\
\hline 24 & 2.1 & 16.9 & 0.73 & 7.0 & 11.2 & 1.44 & 8.7 & 10.2 & 1.97 & 10.4 & 9.5 & 1.72 \\
\hline 36 & 3.4 & 15.9 & 0.80 & 13.2 & 7.3 & 2.30 & 16.8 & 4.0 & 3.41 & 19.4 & 0.5 & 2.58 \\
\hline 48 & 7.4 & 9.9 & 1.16 & 16.8 & 4.5 & 2.81 & 18.8 & 0.4 & 3.47 & 25.2 & 0.3 & 1.55 \\
\hline
\end{tabular}

Table 2. Effect of shaking speed on cell growth, glycerol consumption, and ethanol production in shaking flask culture of $P$. tannophilus ATCC 32691 
$2.81,3.47 \mathrm{~g} / 1$ 로 증가함을 관찰할 수 있었다. 그러나 $200 \mathrm{rpm}$ 으로 shaking speed를 증가시켜 배양하였을 경우에는 세포성 장은 50, 100, $150 \mathrm{rpm}$ 에 비하여, 보다 더 증가하였고, glycerol 소비도 더 촉진 되었음에도 불구하고, ethanol의 생산은 1.55 $\mathrm{g} / 1$ 로 급격히 감소하였다. 이러한 결과에서 우리는 P. tannophilus ATCC 32691를 이용하여 glycerol로부터 ethanol을 생 산할 경우에 공기의 공급이 매우 중요한 요소이며, 적절한 양 의 공기 공급 조건을 선택하여야만 glycerol로부터 보다 효율 적으로 ethanol을 생산할 수 있다는 결론을 내릴 수 있었다.

\section{Surface aeration을 이용하여 발효조에서 glycerol로 부} 터 ethanol 생산

P. tannophilus ATCC 32691의 Table 2 결과를 바탕으로 surface aeration을 이용하여 미량의 공기를 공급할 수 있는 발효 조(Fig. 1)에서 glycerol로부터 ethanol을 생산하는 최적조건을 탐색하였다(Fig. 3). 본 연구에서는 surface aeration rate을 500 $\mathrm{ml} / \mathrm{min}$ 으로 고정하고, 발효조의 agitation speed를 200에서 $400 \mathrm{rpm}$ 까지 변화시키면서 약 $20 \mathrm{~g} / 1$ 의 glycerol로 부터 ethanol 생산을 관찰하였다. Fig. 3과 같이 agitation speed를 200에 서 부터 $400 \mathrm{rpm}$ 으로 점점 증가시켰을 때, 세포의 성장도 증가 하였고, glycerol의 소비속도도 증가하였다. 그러나 ethanol의 생산은 agitation speed가 $300 \mathrm{rpm}$ 일때 약 $3.3 \mathrm{~g} / 1$ 로 가장 많았고, agitation speed가 $400 \mathrm{rpm}$ 으로 증가하였을 경우에는 오히려 ethanol 생산이 줄어드는 경향을 관찰할 수 있었다 (Fig. 3C). 이 결과로 보아서 surface aeration을 이용하여 발효 조에서 glycerol로부터 ethanol을 생산할 경우에 공기를 500 $\mathrm{ml} / \mathrm{min}$ 으로 공급하면서 agitation speed를 $300 \mathrm{rpm}$ 으로 조절 하는 조건에서 가장 많은 양의 ethanol이 생산될 수 있음을 확인할 수 있었다.

Fig. 3에서 발효조에 surface aeration으로 공기를 공급할 때, 발효조에서의 산소전달계수 $\left(\mathrm{k}_{\mathrm{La}}\right)$, 그리고 여러가지 수율값 $(\mathrm{Ye} / \mathrm{g}, \mathrm{Ye} / \mathrm{x}, \mathrm{Yx} / \mathrm{g})$ 이 agitation speed의 변화와 어떤 연관성 이 있는지에 대하여 Fig. 4 와 같이 조사하여 보았다. 산소전달 계수는 agitation speed가 증가함에 따라서 점진적으로 증가 하는 경향을 보였다[약 1.0 에서 $11(1 / \mathrm{h})$ 에 까지 증가]. 이 값은 일반적으로 shaking flask culture를 수행할 경우에 얻을 수 있는 산소전달계수 값에 해당하며[3], 이 값으로 미루어 보아 본 연구에서의 surface aeration에 의해서는 shaking flask culture를 수행하는 정도의 산소가 전달되었다고 추정할 수 있다. 한편, Fig. 4 에서의 수율값 변화를 분석하여 보면, agitation speed가 $400 \mathrm{rpm}$ 에서 ethanol 생산이 감소하는 현상 $(\mathrm{Ye} / \mathrm{g}$ 의 감소)은 $\mathrm{Ye} / \mathrm{x}$ 값의 상대적으로 감소가 원인인 것으로 추론되 며, agitation speed가 낮은 조건인 $200 \mathrm{rpm}$ 에서 $\mathrm{Ye} / \mathrm{g}$ 의 감소 는 $\mathrm{Yx} / \mathrm{g}$ 값 감소로부터 기인된다고 생각되어진다. 종합하면, $300 \mathrm{rpm}$ 에서 ethanol이 많이 생산된 것(상대적으로 가장 큰 $\mathrm{Ye} / \mathrm{g}$ 값=약 0.15 )은 상 대적으로 $\mathrm{Ye} / \mathrm{x}$ 와 $\mathrm{Yx} / \mathrm{g}$ 값이 200, 250,
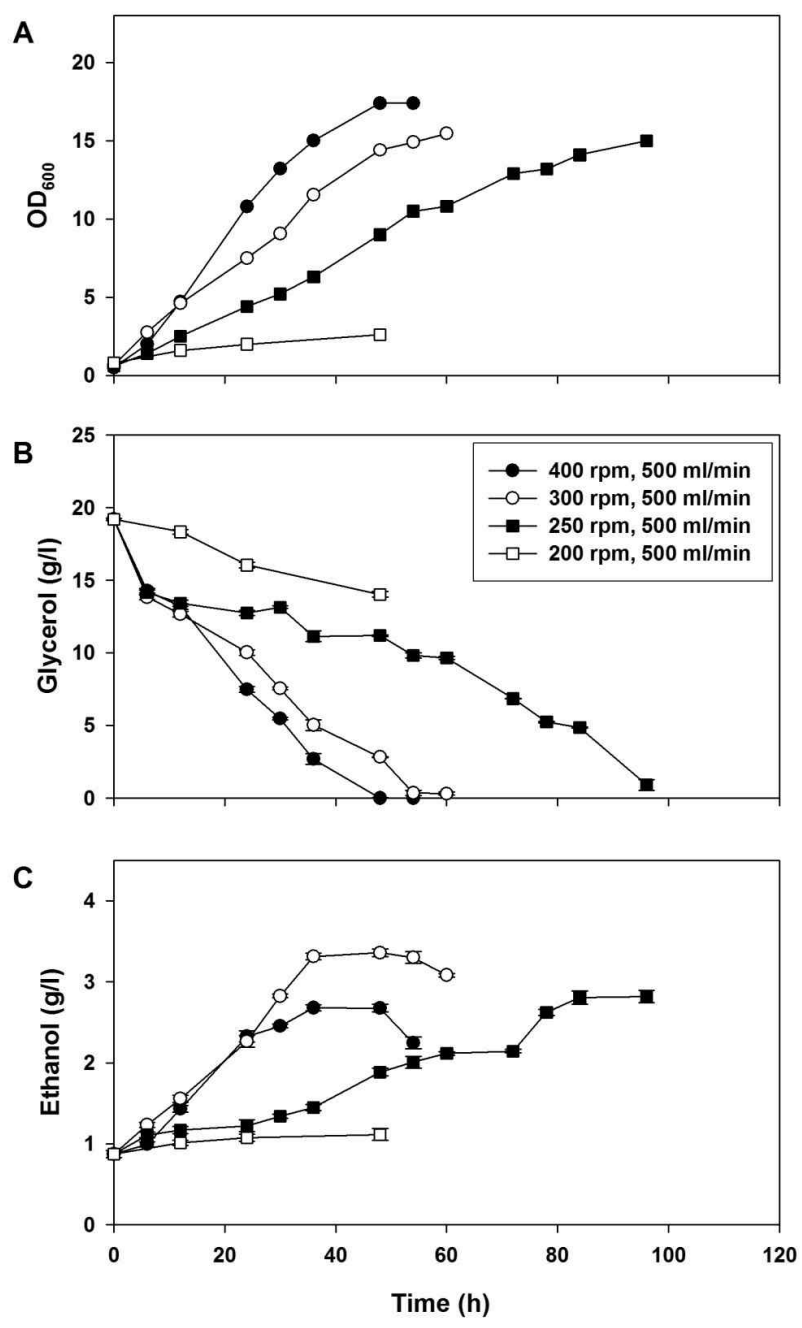

Fig. 3. Surface-aerated fermentor culture of $P$. tannophilus ATCC 32691 for ethanol production from glycerol. (A) Cell concentration (OD at $600 \mathrm{~nm}$ ), (B) residual glycerol concentration, and $(\mathrm{C})$ ethanol concentration are shown. Culture volume; $880 \mathrm{ml}$. Surface aeration rate; 500 $\mathrm{ml} / \mathrm{min}$. Agitation speed; $400 \mathrm{rpm}(\mathbf{O}), 300 \mathrm{rpm}(\bigcirc)$, $250 \mathrm{rpm}(\boldsymbol{\square}), 200 \mathrm{rpm}(\square)$. Measurements of glycerol and ethanol were performed three times using the same sample, and the average and standard deviation were calculated.

$400 \mathrm{rpm}$ 에서 보다 크게 감소하지 않았기 때문인 것으로 생각 되어진다.

이미 언급하였듯이, 효모 P. tannophilus에서 glycerol로 부 터 ethanol 생성에 관한 정확한 대사경로에 대한 보고는 없으 나, xylose에서 ethanol을 생성할 경우와 마찬가지로 glycerol 로 부터 ethanol을 만들 때, 약간의 oxidative metabolism이 필요한 것은 확실하다고 할 수 있다. 그러나, 세균의 대사경로 로부터 유추하여 볼 때, glycerol로부터 ethanol을 생성할 때, 추가적인 reducing power의 공급이 필요하기 때문에 oxidative metabolism이 필요한 것은 아닌 것으로 생각되어진다. 그러 


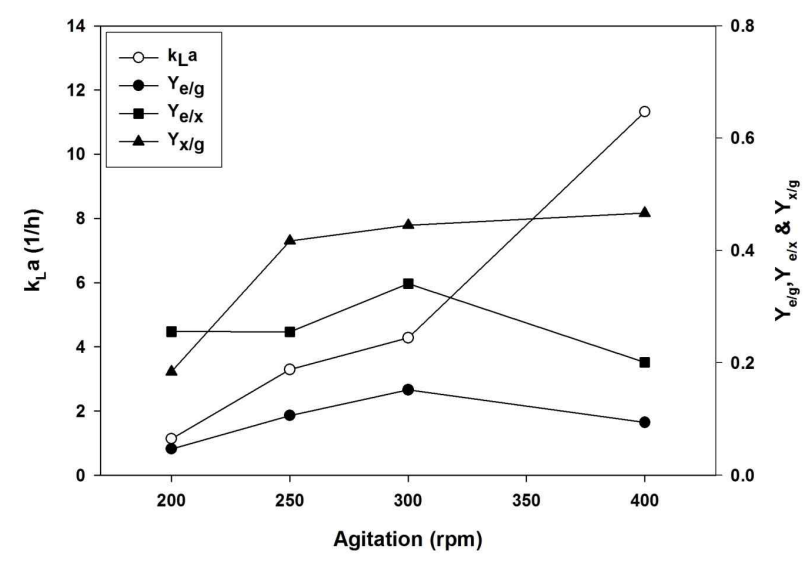

Fig. 4. Effects of agitation speed on $\mathrm{k}_{\mathrm{L}} \mathrm{a}(\bigcirc), \mathrm{Ye} / \mathrm{g}(\mathbf{O}), \mathrm{Ye} / \mathrm{x}$ $(\boldsymbol{\square}), \mathrm{Yx} / \mathrm{g}(\mathbf{\Delta})$ in surface-aerated fermentor culture of Fig. 3.

나, 미량의 공기공급이 P. tannophilus에서 glycerol로 부터 ethanol을 만들 때, 필수적인 공정조절 인자임은 분명하기 때 문에, 공기공급에 대한 정교한 조절이 매우 중요한 것임은 분 명하다 할 수 있겠다.

본 연구에서 사용한 $880 \mathrm{ml}$ 의 배양 부피를 기준으로 $P$. tannophilus ATCC 32691을 이용한 glycerol로부터 ethanol을 생산하는 최적 조건은 $500 \mathrm{ml} / \mathrm{min}$ 의 공기를 surface aeration 방법으로 공급하면서, $300 \mathrm{rpm}$ 의 agitation speed로 운전 할 경우라고 결론 내릴 수 있는데, $\mathrm{Liu}$ 등[12]의 결과에서는 $\mathrm{Ye} / \mathrm{g}$ 값이 본 연구 보다 2배 이상 큰 최고 0.28 로 보고하고 있다. 그러나, 본 연구에서는 YPG 배지를 사용하였고, Liu 등[12]은 yeast nitrogen base w/o amino acids가 포함된 defined medium을 사용하였으며, 또한 공기공급 방법도 본 연구와 상이하기 때문에 $\mathrm{Ye} / \mathrm{g}$ 값을 직접 비교하기는 어렵다고 생각 된다. 그래서 본 연구에서 사용한 배지를 기반으로 ethanol 생산 수율값 $(\mathrm{Ye} / \mathrm{g})$ 증가를 위한 후속 연구가 추가로 필요하다 고 생각되어진다. 한편, 본 연구를 통하여 얻은 ethanol 생산을 위한 최적조건에서의 산소전달계수 값은 대량생산을 위한 scale-up 지표로 사용될 수 있을 것으로 생각된다.

\section{Glycerol로부터 ethanol 생산을 위한 surface-aerated} fed-batch culture

Fig. 3의 결과에서 얻은 최적 surface aeration 조건을 바탕 으로 glycerol을 중간에 첨가하는 fed-batch 배양을 실시하여 보았다. Fig. 5와 같이 약 $20 \mathrm{~g} / 1$ 의 glycerol이 들어 있는 배지를 이용하여 배양을 시작한 후, 3 회에 걸쳐 glycerol이 들어있는 배지를 첨가하였다. 배양 시작 후, 90 시간에 이르러 ethanol이 최고 $5.74 \mathrm{~g} / 1$ 생산되었고, 이때까지의 glycerol에 대한 etha$\mathrm{nol}$ 수율 $(\mathrm{Ye} / \mathrm{g})$ 은 0.166 이었다. 그러나, 두 번째 glycerol이 들어 있는 배지 첨가 후 부터는 세포성장, glycerol 소비, etha$\mathrm{nol}$ 생산이 감소되는 현상이 관찰되었고, 결국에는 glycerol
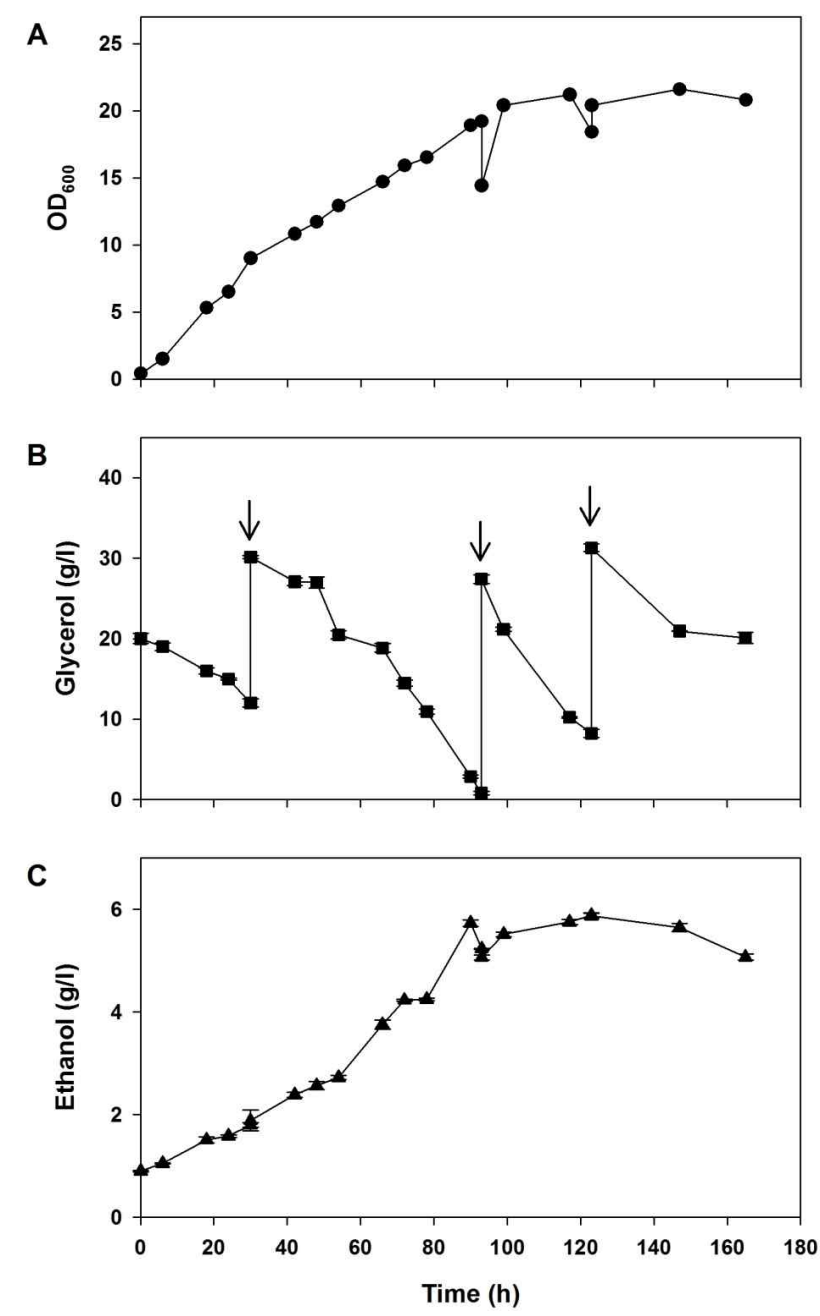

Fig. 5. Fed-batch culture of $P$. tannophilus ATCC 32691 in surface-aerated fermentor forethanol production from glycerol. Culture volume; $880 \mathrm{ml}$. Surface aeration rate; $500 \mathrm{ml} / \mathrm{min}$. Agitation speed; $300 \mathrm{rpm}$. The arrows indicate the times when the medium was fed. Measurements of glycerol and ethanol were performed three times using the same sample, and the average and standard deviation were calculated.

만 천천히 소비되고, 세포성장과 ethanol 생산은 거의 중지되 었다. 이러한 fed-batch 배양을 통하여 완전하지 않았지만, ethanol 생산을 좀 더 연장하여 생산 할 수 있는 가능성을 확인 하였다. Ethanol 생산을 위하여 YPG 배지를 사용하였기 때문 에 배지에 대한 재설계를 통하여 fed-batch 배양 후반부의 문 제점을 해결할 수 있을 것으로 생각되어진다. 또한, ethanol 생산이 멈추기 시작하는 90 시간 정도에 배양액을 빼내고, 새 로운 배지로 교체하여 fed-batch 배양을 계속 진행하는 배양 방법(withdrawal and fill method)인 repeated fed-batch 배양 법을 사용한다면, 위의 문제점을 극복할 수 있을 것으로 생각 되어진다. 


\section{결 론}

P. tannophilus ATCC 32691를 이용하여 glycerol로 부터 ethanol을 생산할 수 있었다. 이 때 미량의 공기공급이 중요하 다는 것을 확인하였고, 이를 위하여 surface-aerated fermentor 를 사용하여 YPG 배지의 glycerol로 부터 ethanol을 생산하는 조건을 조사하였다. 최적 ethanol 생산 조건은 $880 \mathrm{ml}$ 의 배양 액에 $500 \mathrm{ml} / \mathrm{min}$ 의 공기를 surface aeration 방법으로 공급하 면서, $300 \mathrm{rpm}$ 의 agitation speed로 운전할 경우였으며, 이 조 건을 이용하여 fed-batch 배양을 실시한 결과 배양시작 후, 90 시간에 이르러 ethanol이 최고 $5.74 \mathrm{~g} / 1$ 생산되었고, glycerol 에 대한 ethanol 수율 $(\mathrm{Ye} / \mathrm{g})$ 은 0.166 이었다.

\section{감사의 글}

이 연구는 한국해양과학기술원(Korea Institute of Ocean Science and Technology)의 연구비지원(Project No. PE98931) 에 의하여 이루어졌으며, 이에 심심한 감사를 드립니다.

\section{References}

1. Abbaszaadeh, A., Ghobadian, B., Omidkhah, M. R. and Najafi, G. 2012. Current biodiesel production technologies: A comparative review. Energy Convers Manag 63, 138-148.

2. Amaral, P. F. F., Ferreira, T. F., Fontes, G. C. and Coelho, M. A. Z. 2009. Glycerol valorization: New biotechnological routes. Food Bioprod Process 87, 179-186.

3. Atkinson, B. and Mavituna, F. 1983. Biochemical engineering and biotechnology handbook, pp. 771, The nature press, New York, NY, USA.

4. Bondioli, P. and Bella, L. D. 2005. An alternative spectrophotometric method for the determination of free glycerol in biodiesel. Eur J Lipid Sci Technol 107, 153-157.

5. Choi, W. J., Hartono, M. R., Chan, W. H. and Yeo, S. S. 2011. Ethanol production from biodiesel-derived crude glycerol by newly isolated Kluyvera cryocrescens. Appl Microbiol Biotechnol 89, 1255-1264.

6. Clomburg, J. M. and Gonzalez, R. 2013. Anaerobic fermentation of glycerol: a platform for renewable fuels and chemicals. Trends Biotechnol 31, 20-28.

7. Demirbas, A. 2009. Progress and recent trends in biodiesel fuels. Energy Convers Manag 50, 14-34.
8. Dobson, R., Gary, V. and Rumbold, K. 2012. Microbial utilization of crude glycerol for the production of value-added products. J Ind Micribiol Biotechnol 39, 217-226.

9. Gancedo, C., Gancedo, J. M. and Sols, A. 1968. Glycerol metabolism in yeasts; Pathways of utilization and production. Eur J Biochem 5, 165-172.

10. Klingenberg, M. 1970. Localization of the glycerol-phosphate dehydrogenase in the outer phase. Eur J Biochem 13, 247-252.

11. Lee, S. -E., Lee, J. -E., Shin, G. -Y., Choi, W. Y., Kang, D. -H., Lee, H. -Y. and Jung, K. -H. 2012. Development of practical and cost-effective medium for the bioethanol production from the seaweed hydrolysate in surface-aerated fermentor by repeated-batch operation. J Microbiol Biotechnol 22, 107- 113 .

12. Liu, X., Jensen, P. R. and Workman, M. 2012. Bioconversion of crude glycerol feedstocks into ethanol by Pachysolen tannophilus. Bioresour Technol 104, 579-586.

13. Maleszka, R., Wang, P. Y. and Schneider, H. 1982. Ethanol production from D-galactose and glycerol by Pachysolen tannophilus. Enzyme Microb Technol 4, 349-352.

14. Oh, B. -R., Seo, J. -W., Heo, S. -Y., Hong, W. -K., Luo, L. H., Joe, M. -H., Park, D. -H. and Kim, C. H. 2011. Efficient production of ethanol from crude glycerol by a Klebsiella pneumoniae mutant strain. Bioresour Technol 102, 3918-3922.

15. Rywiñska, A., Juszczyk, P., Wojtatowicz, M., Robak, M., Lazar, Z., Tomaszewska, L. and Rymowicz, W. 2013. Glycerol as a promising substrate for Yarrowia lipolytica biotechnological applications. Biomass Bioenergy 48, 148-166.

16. Salvi, B. L. and Panwar, N. L. 2012. Biodiesel resources and production technologies - A review. Renewable Sustainable Energy Rev 16, 3680-3689.

17. Shuler, M. L. and Kargi, F. 2002. Bioprocess engineering, Basic concepts, pp. 292-297, 2nd ed., Prentice-Hall Inc., NJ, USA.

18. Yazdani, S. S. and Gonzalez, R. 2007. Anaerobic fermentation of glycerol: a path to economic viability for the biofuels industry. Curr Opin Biotechnol 18, 213-219.

19. Yeon, J. -H., Lee, S. -E., Choi, W. Y., Choi, W. -S., Kim, I. -C., Lee, H. -Y. and Jung, K. -H. 2011. Bioethanol production from the hydrolysate of rape stem in a surface-aerated fermentor. J Microbiol Biotechnol 21, 109-114.

20. Yeon, J. -H., Lee, S. -E., Choi, W. Y., Kang, D. -H., Lee, H. -Y. and Jung, K. -H. 2011. Repeated-batch operation of surface-aerated fermentor for bioethanol production from the hydrolysate of seaweed Sargassum sagamianum J Microbiol Biotechnol 21, 323-331. 
초록 : Surface-aerated fermentor에서 Pachysolen tannophilus를 이용한 glycerol로 부터 ethanol 생산

김이옥 $\cdot$ 최운용 ${ }^{2} \cdot$ 강도형 $^{3} \cdot$ 이현용 ${ }^{4} \cdot$ 정경환 $^{1}{ }^{*}$

('한국교통대학교 생명공학과, ${ }^{2}$ 강원대학교 의생명소재공학과, ${ }^{3}$ 한국해양과학기술원, ${ }^{4}$ 서원대학교 식품공학과)

본 연구에서 glycerol에서 ethanol을 생산할 수 있는 P. tannophilus ATCC 32691를 선별하여, ethanol 생산조건 에 대하여 조사하였다. Ethanol 생산 시, 미량의 공기 공급이 매우 중요함을 확인하였고, 이를 위하여 발효조에서 surface aeration 방법을 통하여 ethanol 생산을 시도하였다. Glycerol이 포함된 YPG 배지 (1\% yeast extract, $2 \%$ peptone, $2 \%$ glycerol)에서 ethanol을 생산하는 최적 조건은 $880 \mathrm{ml}$ 의 배양액에 $500 \mathrm{ml} / \mathrm{min}$ 의 공기를 surface aeration 방법으로 공급하면서, $300 \mathrm{rpm}$ 의 agitation speed로 운전할 경우였다. 이 조건을 이용하여 fed-batch 배 양을 실시한 결과 배양시작 후, 90시간에 이르러 ethanol이 최고 $5.74 \mathrm{~g} / 1$ 생산되었고, glycerol에 대한 ethanol 수율 $(\mathrm{Ye} / \mathrm{g})$ 은 0.166 이었다. 